\title{
The Cultural Shaping and Value Realization of Digital Media Art
}

\author{
Zhao Hui, Wang Xiaoyan \\ Shandong Xiehe University, Jinan, Shandong, China, 250109
}

Keywords: digital media art; cultural shaping; value realization

\begin{abstract}
With the development of computer multimedia technology and the application of wireless Internet technology, digital media art is a new art form constantly creating new miracles in the art field. Although many traditional artists still have doubts about the artistic expression of digital media, but it can't stop digital media showing its pride in the new media and art platforms. Based on digital technology and modern media, this new art form combines perceptual thinking with rational thinking. At the beginning of the digital media, it showed extraordinary cultural charm and artistic tension. This paper mainly studies the cultural shaping and value realization of digital media art to promote the value of digital media.
\end{abstract}

\section{Introduction}

If digital media art is just an abstract concept until the 21st century, with the widespread application of computer technology, digital media art has become a part of our life. In the art of digital media, not only some young people praise it, but some artists who work in traditional art are also gradually facing the unique charm. The development of digital media art shows the arrival of a new era of culture, which incloud digital image, digital music, mobile phone video, digital film, digital media art and popularity of civilians. Digital media art has become an important part of leisure life and self-pleasure.

\section{Multiple Cultures Contained in Digital Media Art}

Digital media art contains multiple cultural meanings. Such as, good and evil, beauty and ugliness, individual and group, creation and parody, deconstruction and reconstruction, local and world, transmission and management. We can see that the cultural value chain are on every piece of work. There is a chance that the cultural field of digital art will also be able to withstand the impact of both.

\subsection{The moral boundary between good and evil.}

On the cultural platform of digital art, the moral boundary between good and evil is becoming more and more clear. The individual not only has the right to make speech, but also undertakes the moral obligation of "good and evil judgment". Similar "kill orders" are common on the Internet, such as "abuse of cats", "qinghua girls Ming poisoning incident", "bronze gate" and so on. Internet users automatically assume the duty of moral judgment, which causing a great pressure for the parties. And it ultimately affects people's moral judgments.

\subsection{The transformation between beauty and ugliness.}

In the world of digital art, the answer to beauty is rich and varied. We are used to equating the art with the sublime and the beautiful, but the beauty of digital art seems less and less clear. King kong, fly, the complex organisms designed by the computer is also the beautiful things. Unintentionally, the standard of beauty is quietly transformed. This kind of change stimulates people's vision strongly and convulse the spiritual world of the receiver.

\subsection{The creation subject between individuals and groups.}

Digital media art has strong interactivity and result uncertainty, which is related to the pluralistic 
creation subject of digital media art. Compared with traditional art works, digital media art is more important for sharing with others. The audience's experience and participation has been placed in an unprecedented position. On the one hand, the creation process of digital media art itself is completed in the interaction with the audience. On the other hand, audiences have the right to re-create art works. The original creation of a single work may be continued by many people. A piece of work can also be completed by many people. This uncertainty keeps art in motion forever.

To sum up, digital media art contains multiple cultural meanings. No matter how self-disciplined it is, the social reality environment cannot change its cultural attribute and cultural characteristics. We put digital art into the context of social culture, and trace the cultural properties of digital media art. These are great significances for China to build a harmonious socialist society.

\section{The Cultural Value of Digital Media Art}

\subsection{The influence of Internet.}

Internet culture has caused great changes in people's way of thinking and aesthetic value, and online culture has gradually become popular. This greatly broadens people's cultural vision what is happening in society in a unique way. Which has formed a novel cultural value system. In addition, the Internet has created a culture of public service. With the rapid development of media art, the Internet enriches the connotation of culture. Internet culture has evolved from a simple single word or picture into a complex and novel pattern with multimedia technology. Although these pictures are slightly shabby, the spread can be compared to famous paintings. Because this is the picture of people's true life, which is the most appropriate expression of art into life.

\subsection{The influence of film and television animation.}

Digital technology introduces new consumer culture, and people will appreciate all kinds of beautiful digital film and television works, precisely because these works meet their physiological and psychological needs. Cartoon film and television is the complex of people's thoughts and spiritual culture, which is also a comprehensive embodiment of the popular culture. Each country's film and television works have its own unique expression and ideological connotation, which is closely related to the culture of the country. Animation film and television represents a nation's understanding and promotion of cultural trends, expressing some truth and beauty in life, as well as the author's thoughts on life. A good film and television works often bring visual and spiritual shock, which is also the charm of contemporary media.

\subsection{The inheritance of traditional media culture.}

Digital media art has historical responsibility to preserve and inherit traditional culture and art. Its cultural value is immeasurable. Movies and television create new stories by using historical figures as background themes. The film and television creation is based on historical stories and creates new creations. It plays an important role in inheriting traditional culture.

\section{Cultural Shaping of Digital Media Art}

\subsection{Determining grassroots culture.}

Many traditional art forms are too abstract or theoretical in the process of research and discussion. So, although some artists have very high personal culture and their artistic works are rich in connotation, but they are really far away from the real life of the people. Public awareness of these artistic and cultural smells is either in museums, libraries, or in some very professional lectures. This is not enough for people who have already met material needs. Everyone can make use the camera to capture some simple scenario in life, a picture of a typical multimedia image is generated with slightly photographic or environment. Although these pictures are a bit shabby compared to the tens of millions of famous paintings, the market they spread is no less impressive than those of famous paintings. 


\subsection{Promoting aesthetic culture.}

Some of the more powerful artists, no matter what kind of art they are engaged in, are trying to claim that heir own aesthetic views are correct. Digital media art completely subverts traditional aesthetics. Digital media art is based on the people's perspective. After defining the beauty and ugliness in the form of artistic expression, the public determines whether it is worth spreading. The difference is that in the process of communication, there will be more people to evaluate it. Then there will be many different opinions. In fact, this is the real art. Art beauty is too abstract. The definition of beauty and ugliness is completely ambiguous. The beauty demanded by art is not the beauty of a person's attention that is recognized by the public. There is no physical barrier between art and life, and sometimes it may be that a little people's ideas distort the aesthetics of art.

\subsection{Establishing moral culture.}

Any form of art depends on the development of society and technology. The popularity of digital media art is inseparable from the popularization of computer technology. Based on digital technology and modern media, this new art form combines perceptual thinking with rational thinking. At the beginning of the birth, it showed extraordinary cultural charm and artistic tension. In the form of traditional artistic expression, many artists show their individual ability. In order to pursue the artistic value, we often disregard the basic moral standards. However it is completely nonexistent in digital media art. The actual artistic is completely intuitive moral standard. This moral standard is fully integrated with real life. Some sociologists have criticized the "human flesh search" as a serious violation of the privacy. But it completely ignores the fact that these people are being searched, which is the result of a serious distortion of moral values. In an Internet environment, the "quack hunt" or "human flesh search plan" is an intrusion on personal information.

\section{The Value of Digital Media Art}

No matter what kind of art, it is inseparable from the realization of value. Because only by showing its value, can we get a better opportunity. Contrast with traditional art forms, Digital media art is more inclined to the pursuit of economic benefits.

\subsection{High added value.}

Because digital media art is more attached to the development of Internet environment, both its propagation speed and its transmission range are higher and wider than traditional art forms. Its base is big and funny, and the added value has reached a height. Only the correct evaluation and analysis is the most accurate understanding of digital media art form.

\subsection{The group affects.}

Digital media art has developed to a relatively high level, but mostly young people pay attention. Many older people do not agree with digital media art. Most young people do not have a high level of pursuit of money and material things, and they mainly pursue spiritual enjoyment. So, it also directly leads to the high social recognition of digital media art, but the phenomenon of low economic effect. So, there will be the phenomenon that one of painting is worth of tens of millions, but a multi-media animation with hundreds of people working hard is noly worth of tens of thousands of yuan.

\subsection{Value improving.}

The effect of digital media art has a lot of room for improvement, which is directly related to national conditions, social integration and people's acceptance. China has just started to contact with some art forms after reaching a well-off level. The art of digital media is only a decade, and it is unrealistic to devote more attention. No matter what kind of art form, we should pay attention to the gradual process of being accepted and accepted. Although digital media art can't be supported in the traditional form of art, this kind of support can't be arbitrarily added to the public's personal feelings. Compared with traditional manual operation art, digital media art integrates digital technology into 
computer technology. Thus, the unique style of digital media art is displayed in the fields of image, audio and communication. Some artists and digital fans do not understand the aesthetic characteristics when they use digital media to create a work. So, they can not use digital media to express their true feelings. The works created are not supported by the soul, which is not conducive to the innovation.

\section{Conclusion}

The development of digital media art has a long way. Only theoretical research is empty, and the development is just a dream without specific artistic creation. The concrete practice in the digital media art produces a clearer understanding of the cultural shaping and value construction. It is the purpose that we can realize the mutual verification of theory and practice.

\section{References}

[1] Marita Sturken and Lisa Cartwright: Practices of Looking: AnIntroduction to Visual Culture. Oxford University Press. (2001) 83-87

[2] W. J. T. Mitchell: Showing Seeing a Critique of Visual Culture, in Nicholas Mirzoeffed. The Visual Culture Reader. London: Routledge. (2011) 80-875

[3] Bonet, B. and Geffner. Planning as heuristic search. Artificial Intelligence: Special Issueon Heuristic Search. (2011) 5-33

[4] Cavazza, M. Lugrin, JL. Crooks, S. Nandi, A. Palmer, M. Le Renard, M.: Causalityand Virtual Reality Art, Fifth ACM International Conference on Creativity and Cognition. Goldsmiths College, London. (2015) 22-28

[5] Grau,O. Virtual Art:From Illusion to Immersion ,Cambridge (Massachussets). MITpress. ISBN. (2002) 88-92

[6] Jacobson, J. Hwang, Z. Unreal Tournament for Immersive Interactive Theater. Communications of the ACM, (2002) 39-42

[7] Lewis, M and Jacobson, J.: Games Engines in Scientific Research. Communications of ACM, (2002) 27-31

[8] Macedo, L, Cardoso, A.: Modelling Forms of Surprise in an Artificial Agent, in Proc. ofthe 23rd Annual Conference of the Cognitive Science Society. 23rd Annual Conference ofthe Cognitive Science Society, Edinburgh. (2011) 588-593 